\title{
Increase of Magnetic Transition Temperatures by Reduction of Local Disorder for Perovskite Manganites
}

\author{
B. Dabrowski, O. Chmaissem, J. Mais, S. Kolesnik, J.D. Jorgensen ${ }^{1}$, and S. Short ${ }^{1}$, \\ Department of Physics, Northern Illinois University, DeKalb, IL 60115 \\ ${ }^{1}$ Materials Science Division, Argonne National Laboratory, Argonne, IL 60439
}

\begin{abstract}
We report the synthesis of $\mathrm{Sr}_{1-\mathrm{x}} \mathrm{Ca}_{\mathrm{x}} \mathrm{MnO}_{3}$ and $\mathrm{La}_{0.5} \mathrm{Ba}_{0.5} \mathrm{MnO}_{3}$ perovskites over extended cation and oxygen composition ranges and describe the dependence of their phase stability on the tolerance factor $\mathrm{t}=\mathrm{t}(\mathrm{x}, \mathrm{T}, \delta)$ that is a function of composition, temperature, and oxygen content. We show that magnetic transition temperatures depend strongly on the tolerance factor and charge disorder while dependence on the structural disorder is less important. By reducing charge and structural disorder we have significantly increased the Curie and Neel temperatures for perovskite manganites.
\end{abstract}

Perovskite manganites, $\mathrm{AMnO}_{3}$, have been recently studied in great detail because of very interesting magnetic and electronic properties resulting from competing charge, exchange, and phonon interactions [1]. The properties can be tuned over a wide range through the choice of the sizes and charges of the A-site cations that control the degree of structural distortions and the formal valance of $\mathrm{Mn}$. The correlation of physical properties with the $\mathrm{Mn}-\mathrm{O}-\mathrm{Mn}$ bond-angle controlled electronic band-width has been clearly established for decades [2,3]. These correlations are also frequently described in terms of the average structure using a concept of tolerance factor $\mathrm{t}=[\mathrm{A}-\mathrm{O}] / \sqrt{2}[\mathrm{Mn}-\mathrm{O}][4]$. Here, $[\mathrm{A}-\mathrm{O}]$ and $[\mathrm{Mn}-\mathrm{O}]$ are the average cationoxygen interatomic distances of the A- and B-sites, respectively, the approximate values of which can be obtained from the ionic sizes that are tabulated for various coordination numbers and oxidation states at room temperature [5]. It was reported recently that the ferromagnetic transition temperatures can be better accounted for by using in addition to the tolerance factor the variance of sizes of the A-site ions, $\mathrm{s}(\mathrm{x})=\sqrt{ } \Sigma_{\mathrm{i}}\left\{x_{i}\left[\mathrm{~A}_{\mathrm{i}}-\mathrm{O}\right]^{2}-[\mathrm{A}-\mathrm{O}]^{2}\right\}$, where $[\mathrm{A}-\mathrm{O}]=\Sigma_{\mathrm{i}} x_{i}\left[\mathrm{~A}_{\mathrm{i}}-\mathrm{O}\right]$, 
and $x_{i}$ is the fractional occupancy of atoms occupying the A-site [4]. The effects of local structural distortions have been studied most extensively for the mixed valent manganites $\mathrm{La}_{1 \text { - }}$ ${ }_{x} \mathrm{~A}_{\mathrm{x}} \mathrm{MnO}_{3}(\mathrm{~A}=\mathrm{Ca}, \mathrm{Sr}, \mathrm{Ba})[6,7,8,9]$. To date, studies of these materials were limited by the substitution level $\mathrm{x}_{\mathrm{s}}$ of the A metal, beyond which formation of the perovskite phase was not possible because of the decreasing average size of the $\mathrm{Mn}^{3+\mathrm{x}}$ ion and the unfavorable tolerance factor $\mathrm{t} \geq 1$ of the desired composition.

With modified synthesis methods at reduced oxygen pressure we recently have been able to extended the solubility limits from $\mathrm{x}_{\mathrm{s}}=0.6$ and 0.3 to $\mathrm{x}_{\mathrm{s}}=1$ and 0.7 for $\mathrm{La}_{1-\mathrm{x}} \mathrm{Sr}_{\mathrm{x}} \mathrm{MnO}_{3-\delta}$ and $\mathrm{La}_{1-\mathrm{x}} \mathrm{Ba}_{\mathrm{x}} \mathrm{MnO}_{3-\delta}$, respectively [10,11]. These results are in disagreement with the much smaller values of $\mathrm{x}_{\mathrm{s}}=0.46$, and 0.27 which are predicted for $\mathrm{Sr}$, and $\mathrm{Ba}$, respectively, based on tolerance-factor arguments using tabulated interatomic distances [5]. In this paper we report the synthesis of the $\mathrm{Sr}_{1-\mathrm{x}} \mathrm{Ca}_{\mathrm{x}} \mathrm{MnO}_{3}$ and $\mathrm{RE}_{0.5} \mathrm{Ba}_{0.5} \mathrm{MnO}_{3}$ compounds over an extended cation and oxygen composition range and describe the dependence of their phase stability on a newly calculated tolerance factor that explains the expanded solubility limits. We show that for a single-valent $\mathrm{Mn}^{4+}$ compound $\mathrm{Sr}_{1-\mathrm{x}} \mathrm{Ca}_{\mathrm{x}} \mathrm{MnO}_{3}$ the variance of sizes of the A-site ions suppresses the antiferromagnetic transition temperature by a maximum of $\sim 20 \mathrm{~K}$ at $\mathrm{x}=0.5$ where $\mathrm{s}(\mathrm{x})$ is the largest. By comparing ferromagnetic transition temperatures of the two structural forms of $\mathrm{RE}_{0.5} \mathrm{Ba}_{0.5} \mathrm{MnO}_{3}$ compounds studied by neutron diffraction, disordered (with randomly mixed $\mathrm{RE} / \mathrm{Ba}$ ) and ordered (forming $\mathrm{Ba} / \mathrm{RE} / \mathrm{Ba}$ layers along the c-axes), we show that a decrease of the local A-site charge disordering induces a large, $\sim 80 \mathrm{~K}$, increase of the ferromagnetic $\mathrm{T}_{\mathrm{c}}$.

To improve the calculation of the tolerance factor we have used neutron powder diffraction to precisely measure the $\mathrm{A}-\mathrm{O}$ and $\mathrm{Mn}-\mathrm{O}$ bond lengths and derive accurate interatomic distances [Ca-O], [Sr-O], [Ba-O], and [Mn-O] rather than relying on tabulated values [12]. The temperature dependence of the tolerance factor was then calculated from the measured bond lengths where weighted averages were defined to account for the unusual coordination. By using thermogravimetric measurements of oxygen deficiency $\delta$ and parameterizing the measured tolerance factor, we have obtained the functional dependence of the tolerance factor $\mathrm{t}=\mathrm{t}(\mathrm{x}, \mathrm{T}, \delta)$ on composition, temperature, and oxygen content. At a fixed oxygen content, the tolerance factor is an increasing function of temperature as a result of greater thermal expansion of the

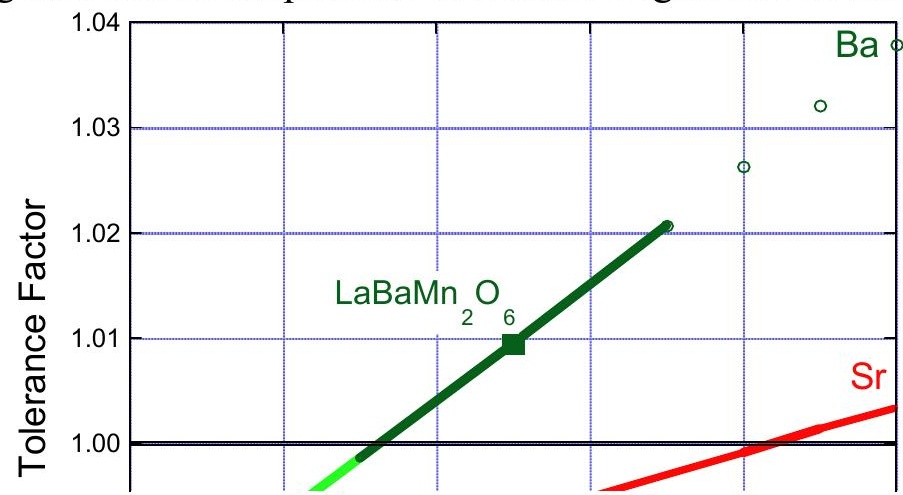


Fig. 1 Tolerance factor as a function of composition for $\mathrm{La}_{1-\mathrm{x}} \mathrm{A}_{\mathrm{x}} \mathrm{MnO}_{3}$ system $(\mathrm{A}=\mathrm{Ba}, \mathrm{Sr}, \mathrm{Ca})$ at room temperature. Dark solid lines denote extended solid solution ranges for $\mathrm{A}=\mathrm{Ba}$ and $\mathrm{Sr}$.

average [A-O] bond relative to the average [Mn-O] bond. The stability of the perovskite phase at high temperature (where synthesis is done) is governed, as expected, by the magnitude of the tolerance factor $(\mathrm{t} \leq 1)$ which can be adjusted by controlling the average interatomic distance $\left[\mathrm{Mn}^{4-2 \delta}-\mathrm{O}\right]$ as a function of the oxygen content $3-\delta$. This dependence of the tolerance factor on oxygen content and temperature has been utilized for the controlled formation of the $\mathrm{Sr}_{1}$ ${ }_{\mathrm{x}} \mathrm{Ca}_{\mathrm{x}} \mathrm{MnO}_{3}$ and $\mathrm{RE}_{0.5} \mathrm{Ba}_{0.5} \mathrm{MnO}_{3}$ phases. The synthesis have been done in two steps: Formation of the oxygen-deficient $\left(\mathrm{O}_{2.5-2.8}\right)$ perovskite framework at high temperature $(1300-1400 \mathrm{C})$ and low oxygen pressure (Ar or $\mathrm{H}_{2} / \mathrm{Ar}$ flow), followed by the complete oxygenation (air or $\mathrm{O}_{2}$ flow) at a temperature low enough (below $500 \mathrm{C}$ ) that the cations do not diffuse. Formation of the well layered-ordered $\mathrm{RE}_{0.5} \mathrm{Ba}_{0.5} \mathrm{Mn}_{3-\delta}$ phases at high temperatures required accurate control of the oxygen content at $\mathrm{O}_{2.5}$.

Figure 1 shows the tolerance factor as a function of composition for the $\mathrm{La}_{1-\mathrm{x}} \mathrm{A}_{\mathrm{x}} \mathrm{MnO}_{3}$ system at room temperature using our values of interatomic distances $[\mathrm{Ca}-\mathrm{O}]=2.640$, $[\mathrm{Sr}-\mathrm{O}]=$ 2.691, $[\mathrm{La}-\mathrm{O}]=2.765,[\mathrm{Ba}-\mathrm{O}]=2.783,\left[\mathrm{Mn}^{4+}-\mathrm{O}\right]=1.896$, and $\left[\mathrm{Mn}^{3+}-\mathrm{O}\right]=1.990 \AA$. Our values of interatomic distances are similar to the sum of ionic radii obtained from tabulated values [5] for oxygen with $\mathrm{La}$ and $\mathrm{Mn}$. For $\mathrm{Ca}, \mathrm{Sr}$, and $\mathrm{Ba}$ our interatomic distances are significantly smaller than those obtained from tables. As a result there is a considerable discrepancy between tolerance factors obtained from our values and from Shannon's tables [5]. The discrepancy is 


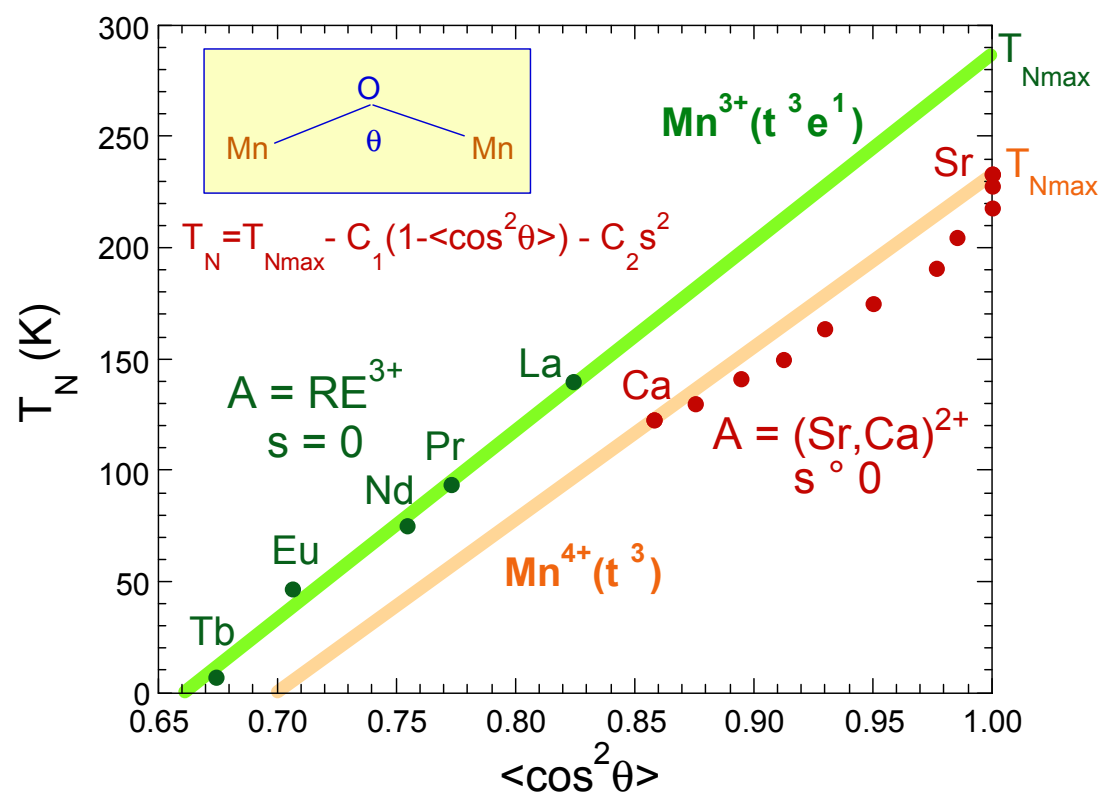

Fig. 2 Neel temperatures vs. average $\cos ^{2}$ of the Mn-O-Mn bond angle for the solid solution system $\mathrm{Sr}_{1-\mathrm{x}} \mathrm{Ca}_{\mathrm{x}} \mathrm{MnO}_{3}$ with a single valent $\mathrm{Mn}^{4+}\left(\mathrm{t}^{3}\right)$ and $\mathrm{REMnO}_{3}(\mathrm{RE}=\mathrm{La}, \mathrm{Pr}, \mathrm{Nd}, \mathrm{Eu}, \mathrm{Tb})$ with the single valent $\mathrm{Mn}^{3+}\left(\mathrm{t}^{3} \mathrm{e}^{1}\right)$ perovskites. The variance of sizes $\mathrm{s}=0$ and $\mathrm{s} \neq 0$ for $\mathrm{REMnO}_{3}$ and $\mathrm{Sr}_{1-\mathrm{x}} \mathrm{Ca}_{\mathrm{x}} \mathrm{MnO}_{3}$, respectively ( $\mathrm{s}=0$ for $\mathrm{Sr}_{1-\mathrm{x}} \mathrm{Ca}_{\mathrm{x}} \mathrm{MnO}_{3}$ with $\mathrm{x}=0$ and 1).

even larger for the variance of sizes of the A-site ions $\mathrm{s}(\mathrm{x})$. Our more accurate interatomic distances derived for manganites should be used for the purpose of correct calculation of $\mathrm{t}(\mathrm{x})$ and $\mathrm{s}(\mathrm{x})$. The unusually short lattice parameter $\left(\mathrm{a}_{\mathrm{o}}=3.805\right)$ (and the interatomic distance of $[\mathrm{Sr}-\mathrm{O}]=$ $\mathrm{a}_{\mathrm{o}} / \sqrt{ } 2 \sim 2.69 \AA$ ) for manganites when compared with the lattice parameters $\mathrm{a}_{\mathrm{o}}=3.869,3.841$, and 3.904 for several cubic perovskites $\mathrm{SrBO}_{3}$ with $\mathrm{B}=\mathrm{Fe}, \mathrm{V}$, and Ti, respectively, may be the cause of these discrepancies.

The two-step synthesis method allowed us to prepare the $\mathrm{Sr}_{1-\mathrm{x}} \mathrm{Ca}_{\mathrm{x}} \mathrm{MnO}_{3}$ and $\mathrm{La}_{0.5} \mathrm{Ba}_{0.5} \mathrm{MnO}_{3}$ compounds with the unusual tolerance factors $\mathrm{t} \sim 1$ and investigate their structural and physical properties. Figure 2 shows Neel temperatures as a function of the Mn-O$\mathrm{Mn}$ bond angle for solid solution system $\mathrm{Sr}_{1-\mathrm{x}} \mathrm{Ca}_{\mathrm{x}} \mathrm{MnO}_{3}$ with single valent $\mathrm{B}=\mathrm{Mn}^{4+}\left(\mathrm{t}^{3}\right)$. Magnetic superexchange interactions in $\mathrm{ABO}_{3}$ perovskites are dependent on the $\mathrm{B}-\mathrm{O}-\mathrm{B}$ bond angle $\phi[3]$. For single valent systems with $\mathrm{B}=\mathrm{Fe}^{3+}\left(\mathrm{t}^{3} \mathrm{e}^{2}\right)$ and $\mathrm{Cr}^{3+}\left(\mathrm{t}^{3}\right)$ it was determined that the antiferromagnetic $\mathrm{T}_{\mathrm{N}} \sim<\cos ^{2} \phi>$ when there is only one kind of Rare Earth on the A-site. Fig. 2 shows that a similar relationship holds for the single valent $\operatorname{Mn}^{3+}\left(t^{3} e^{1}\right)$ compounds. However, for the solid solution system $\mathrm{Sr}_{1-\mathrm{x}} \mathrm{Ca}_{\mathrm{x}} \mathrm{MnO}_{3}$ with a single valent $\mathrm{B}=\mathrm{Mn}^{4+}\left(\mathrm{t}^{3}\right)$, the structural disorder on the A-site introduces measurable deviation from this relation. The size 


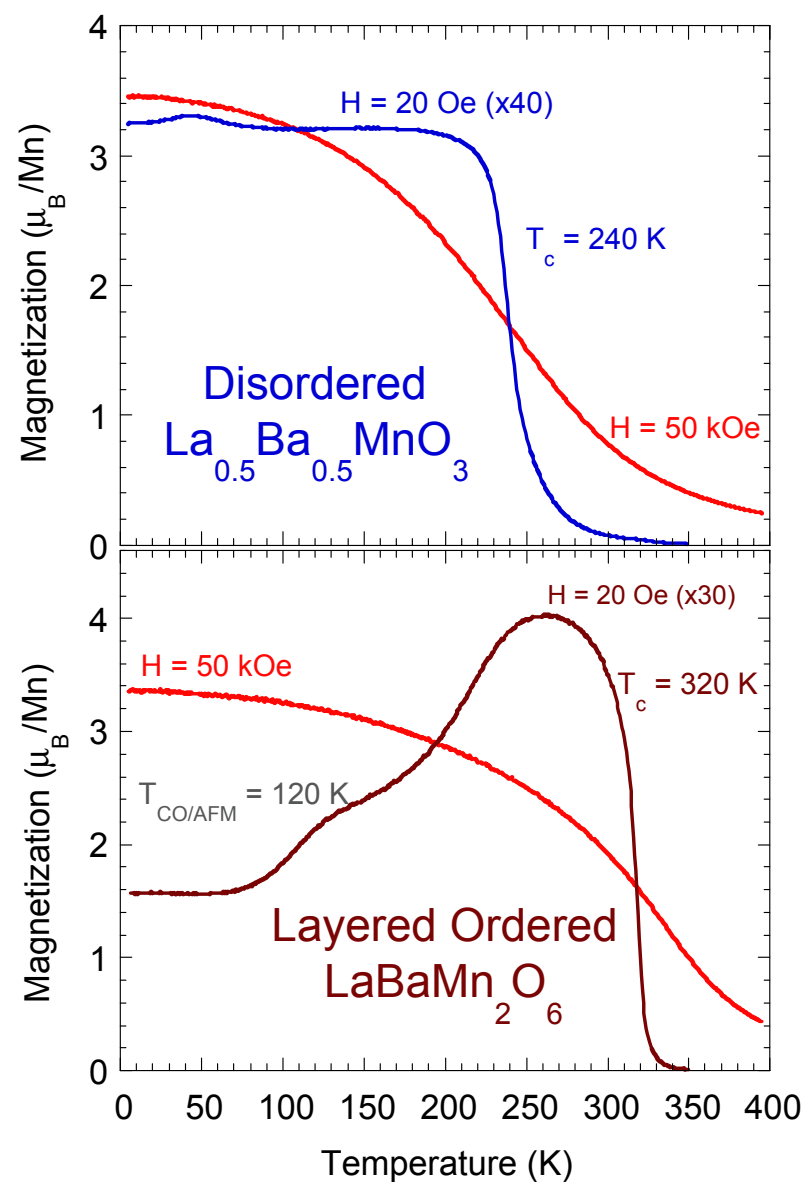

Fig. 3 dc magnetization in low magnetic field $(20$ Oe $)$ and at 5 Tesla for disordered $\left(\mathrm{La}_{0.5} \mathrm{Ba}_{0.5} \mathrm{MnO}_{3}\right)$ and layer ordered $\left(\mathrm{LaBaMn}_{2} \mathrm{O}_{6}\right)$ perovskites with mixed valent $\mathrm{Mn}^{3.5+}$.

difference between interatomic distances of the iso-electronic $\mathrm{Sr}-\mathrm{O}$ and $\mathrm{Ca}-\mathrm{O}$ introduces local variance of the bond angles that suppresses $\mathrm{T}_{\mathrm{N}}$ by $\sim 20 \mathrm{~K}$ at $\mathrm{x}=0.5$ where the variance of sizes is the largest.

Fig. 3 shows much larger effects of the charge disorder on the ferromagnetic transition temperature observed for mixed valent perovskite manganites, $\mathrm{La}_{0.5} \mathrm{Ba}_{0.5} \mathrm{MnO}_{3}$. Because our measured interatomic distances of $[\mathrm{La}-\mathrm{O}]$ and $[\mathrm{Ba}-\mathrm{O}]$ are quite similar, the variance of size, $\mathrm{s}(\mathrm{x})$, is tiny, i.e., the effects of structural disorder are anticipated to be small. Nonetheless, we observe a large, $\sim 80 \mathrm{~K}$, difference of ferromagnetic $\mathrm{T}_{\mathrm{c}}$ between the two structural forms. In addition to a higher $\mathrm{T}_{\mathrm{c}}=320 \mathrm{~K}$ the layered ordered phase displays novel $\mathrm{Mn}^{3+} / \mathrm{Mn}^{4+}$ charge/antiferromagnetic ordering at $\mathrm{T}_{\mathrm{CO} / \mathrm{AFM}}=120 \mathrm{~K}$. We attribute the different properties of the disordered and layeredordered phases to the local A-site charge disordering that profoundly disturbs the coherent electronic states of the Mn-O bonds. The difference between $\mathrm{T}_{\mathrm{c}}$ ' $\mathrm{s}$ of the two structural forms increases with the increase of the variance of sizes for the smaller ionic size $\mathrm{RE}=\mathrm{La}-\mathrm{Nd}$ 
showing that the structural order is also important to preserve the ferromagnetic and chargeordered/antiferromagnetic phases. With a decrease of the RE-O interatomic distances, the $\mathrm{T}_{\mathrm{c}}$ of the disordered phase decreases quickly, the $T_{c}$ of the layered order phase decreases slowly, and the $\mathrm{T}_{\mathrm{CO} / \mathrm{AFM}}$ increases rapidly. The layered ordered compounds with the ionic sizes of the $\mathrm{RE}$ smaller than $\mathrm{Nd}$ have $\mathrm{T}_{\mathrm{c}}<\mathrm{T}_{\mathrm{CO} / \mathrm{AFM}}$; i.e., a novel metal-insulator transition is found that is similar to that observed for the disordered $\mathrm{RE}_{0.5} \mathrm{Sr}_{0.5} \mathrm{MnO}_{3}$ perovskites and which was discussed in terms of the disordered-controlled quantum critical transition [13,14]. We have observed that by stabilizing structurally and charge ordered structures over a wide range of compositions around $\mathrm{x}$ $=0.5$ a substantial increase of the Neel $(520 \mathrm{~K})$ and Curie $(365 \mathrm{~K})$ temperatures can be achieved. Similar effects of local structural/charge order no doubt have profound effects on the properties of other complex oxides; for example, copper oxide high temperature superconductors.

Work at NIU was supported by the ARPA/ONR and by the State of Illinois under HECA. At ANL work was supported by the U.S. Department of Energy - Office of Science under contract No. W-31-109-ENG-38.

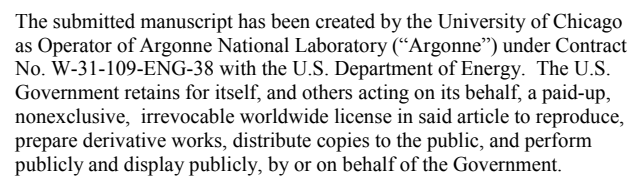

\section{REFERENCES}

$1 \quad$ Y. Tokura and N. Nagaosa, Science 288: (5465) 462-468 (2000).

2 J.B. Goodenough, Wiley, New York, (1963).

3 C. Boekema, F. Van Der Woude, and G.A. Sawatzky, Int. J. Magnetism, 3, 341 (1972).

$4 \quad$ L.M. Rodriguez-Martinez, and J.P. Attfield, Phys. Rev. B 54, R15622 (1996).

$5 \quad$ R.D. Shannon, Acta Crystallogr. Sec. A 32, 751 (1976).

6 A. Urushibara, Y. Moritomo, T. Arima, A. Asamitsu, G. Kido, Y. Tokura, Phys. Rev. B 51, 14103 (1995).

$7 \quad$ P. Schiffer, A.P. Ramirez, W. Bao and S.-W. Cheong, Phys. Rev. Lett. 75, 3336 (1995).

8 H.Y. Hwang, S-W. Cheong, P.G. Radaelli, M. Marezio, and B. Batlogg, Phys. Rev. Lett. 75, 914-917 (1995).

9 F. Millange, V. Caignaert, B. Domenges, B. Raveau, and E. Suard, Chem. Mater. 10, 1974 (1998).

10 O. Chmaissem, B. Dabrowski, S. Kolesnik, J. Mais, D.E. Brown, R. Kruk, P. Prior, B. Pyles, J.D. Jorgensen, Phys. Rev. B 64, 134412 (2001).

11 B. Dabrowski, S. Kolesnik, O. Chmaissem, J. Mais, J.D. Jorgensen, unpublished.

12 B. Dabrowski, O. Chmaissem, J. Mais, and S. Kolesnik, J. D. Jorgensen, and S. Short, unpublished. 
13 H. Kawano, R. Kajimoto, H. Yoshizawa, Y. Tomioka, H. Kuwahara, and Y. Tokura, Phys. Rev. Lett. 78, 4253 (1997).

14 E. Dagotto, T. Hotta, and A. Moreo, Phys. Rep. 344, 1 (2001). 